\title{
Estrategias de apoyo familiar: ¿qué dicen los padres de familia en grupos de Sonora y Morelos?
}

Ana Laura Navarro Romero ${ }^{1}$, Karlena María Cárdenas Espinoza ${ }^{1}$

Alejandro Escobedo García², Mónica Cecilia Dávila Navarro²

y Aldo Bazán Ramírez ${ }^{1}$

\section{Introducción}

Diversos estudios realizados en distintos contextos han mostrado evidencias de que la variable "apoyo familiar" y la expectativa de los padres sobre el futuro académico y laboral de sus hijos son mejores predictores del desempeño académico de los niños, en comparación con variables como "nivel socioeconómico", "nivel educativo de los padres", "expectativas y creencias de los padres" (Bazán, Osuna y Ross, 2003; Bazán, Sánchez y Castañeda, 2007).

Los padres de familia son quienes deciden en qué plantel estudiarán sus hijos, son los que crean la cultura familiar y sus referentes. Principalmente, son quienes gozan de la relación íntima con sus hijos, la cual permite el desarrollo de relaciones interpersonales, de apoyo, de orientación y/o soporte que impactan en el desarrollo integral del niño, independientemente de su nivel educativo, cultural y económico.

1 Universidad Autónoma del Estado de Morelos.

2 Instituto Tecnológico de Sonora. 
Asimismo, se afirma que la escuela necesita de los padres para fortalecer los conocimientos, competencias y valores enseñados en las situaciones de aprendizaje para favorecer los objetivos educativos de la institución, el mejoramiento de la actitud y compromiso de los estudiantes hacia el estudio; sin embargo, los padres necesitan de las escuelas con el fin de que se les proporcione educación a sus hijos y, al mismo tiempo, éstos requieren orientación sobre la manera efectiva de formar a sus hijos y apoyar su aprendizaje.

A pesar de que existen diversas aproximaciones teóricas e investigaciones sobre cómo la escuela incentiva la participación e involucramiento de los padres de familia, no se ha indagado lo suficiente en el estudio del apoyo familiar, con respecto a las estrategias que utilizan los padres de familia para favorecer el desarrollo y éxito académico de sus hijos.

Los factores que influyen en el desempeño académico son la expectativa de los padres de familia sobre la carrera académica de sus hijos, el apoyo en las tareas escolares y la exigencia para que logren niveles altos de desempeño académico, especialmente en contextos socioeconómicos bajos y medio bajos, debido a que al parecer constituyen la necesidad y expectativa de una mejora en el estatus socioeconómico a través de la educación (Bazán, Sánchez y Castañeda, 2007).

\section{Existen diversos modelos}

que explican la participación de la familia en la escuela

Hoover-Dempsey et al. (1992, 1997, 2005) han propuesto un modelo de tres factores para el involucramiento de los padres en el aprendizaje de sus hijos: su construcción del rol parental (responsabilidad y acciones) respecto al desarrollo académico de sus hijos; el sentido de la eficacia (conocimientos y habilidades) para apoyar a sus hijos; y la percepción de la oportunidad para poder involucrarse. Con base en estos factores probabilizadores del involucramiento familiar, señalan tres variables: el dominio específico de habilidades y conocimientos para apoyar al niño; la situación familiar, de empleo y otras demandas familiares que 
probabilizan o dificultan el apoyo; y la invitación y demanda de apoyo de parte del niño o de la escuela para que los padres se involucren.

Asimismo, con base en la propuesta de Renglin (2002) sobre las acciones de involucramiento familiar, Bazán, Sánchez y Castañeda (2007), así como Bazán y Domínguez (en dictamen), han propuesto un modelo de apoyo familiar con cinco elementos: asistencia o apoyo en tareas escolares; tiempo y espacio proporcionado para el estudio; comunicación regular con las figuras docentes; actividades complementarias, repaso y evaluación; y valoración del nivel de aprendizaje y dominio de su hijo (Bazán, Osuna y Ross, 2003).

Los dos primeros modelos se centran más en el involucramiento de los padres de familia por parte de la escuela $y$, en menor medida, en las estrategias de apoyo que los padres utilizan para fortalecer el aprendizaje de sus hijos. Por ello, esta investigación tuvo como propósito explorar las actividades que los padres realizan para apoyar o enseñar a sus hijos en casa y en otros contextos.

El objetivo general del estudio consistió en identificar y clasificar las diversas estrategias de apoyo familiar que utilizan los padres para contribuir al logro académico de sus hijos.

\section{Método}

El presente estudio es de tipo transeccional exploratorio. Tomando como base la experiencia que los padres tienen a diario con sus hijos en lo relacionado a actividades académicas, se pretende identificar cuáles son las estrategias que ellos utilizan para apoyar a sus hijos en las actividades escolares (Hernández, Fernández y Baptista, 2010).

\section{Participantes}

Tanto en Sonora como en Morelos se trabajó con padres de familia de niños con alto rendimiento académico en dos escuelas 
de tres contextos socioeconómicos: rural indígena, urbana pública y privada de clase alta. El criterio de inclusión fue que sus hijos estuvieran cursando el sexto grado de primaria y que tuvieran un alto desempeño académico. En el caso del estado de Morelos, se contó con la participación de doce padres de familia; y en el caso de Sonora, con diez padres.

\section{Instrumentos}

Se elaboró un guión de entrevista con base en las siguientes categorías.

1. Percepción del rol parental (responsabilidad y acciones) respecto al apoyo.

2. Percepción de la oportunidad para poder apoyar (invitación y demanda de apoyo de parte del niño).

3. El sentido de la eficacia (¿tienen o no estrategias?) para apoyar a sus hijos.

4. Tiempo y espacio proporcionado para el estudio.

5. Repaso y evaluación.

6. La situación familiar, de empleo y otras demandas familiares que probabilizan o dificultan el apoyo (tiempo, horarios).

\section{Procedimiento}

Con el objetivo de identificar si las preguntas formuladas permitían indagar las estrategias de apoyo familiar empleadas por los padres, se condujo un grupo focal piloto.

Posteriormente, se replantearon algunas de las preguntas guía y se condujo un grupo focal por cada contexto en ambos estados del país.

\section{Resultados}

Con respecto a las estrategias que utilizan los padres en común para favorecer el alto desempeño académico de sus hijos en los 
tres contextos socioeconómicos, en ambos estados del país, se obtuvo lo siguiente.

Percepción del rol parental respecto al apoyo

Los padres refieren que es importante apoyarlos porque los quieren; en los contextos rurales y urbanos públicos, las respuestas frecuentes fueron que los apoyan para que logren superarse en la vida o para que no pasen las mismas cosas que ellos; en este sentido, los padres se ponen de ejemplo para que los niños sigan estudiando. Una madre de familia comentó: "Nosotros [su esposo y ella] les decimos que somos un espejo para ellos, que no pasen lo que nosotros pasamos, el hecho de que nosotros hayamos sufrido no quiere decir que ustedes sufran".

En cuanto a las actividades que realizan con sus hijos para apoyar su aprendizaje, mencionaron que es importante brindarles confianza y motivarlos para que estudien, mantener buena comunicación con los hijos, crear redes de apoyo con otros familiares o con los maestros, revisarles las tareas, establecer horarios y rutinas, apoyarlos comprando el material, reconocer el esfuerzo que realizan y premiarlos; reconocer sus habilidades, y permitirles que sean responsables en sus actividades académicas.

Percepción de la oportunidad para poder apoyar

Algunos de los padres reportaron un comportamiento identificado cuando los niños tienen dificultades con la tarea, como por ejemplo enojarse, terminar la tarea muy rápido, llorar o no querer empezar la tarea.

La mayoría reporta que los niños expresan abiertamente cuando requieren ayuda, una madre mencionó: "Ella lo expresa y lo dice: 'Sabes qué, mamá, no puedo, no entiendo', y es cuando yo le ayudo".

Para saber si los niños tienen tareas o exámenes, les preguntan a ellos y también revisan cuadernos y libros, esto ocurre en los tres contextos estudiados. En contextos urbanos es co- 
mún que los niños lleven libreta de tareas y esto facilita saber qué actividades tienen que realizar en casa.

\section{El sentido de la eficacia para apoyar a sus hijos}

Cuando hay dudas, los niños preguntan a los padres, y cuando ellos tampoco saben, recurren a sus redes de apoyo: hermanos mayores, familiares, otros maestros, entre otros.

En los contextos urbanos, recurren con mayor frecuencia al uso del Internet que en los contextos rurales, a pesar de que sí cuentan con esta herramienta tecnológica.

La principal actividad que realizan los padres ante una duda es volver a leer la actividad con los niños y explicarles. En los contextos rurales, cuando hay una duda que no pueden resolver, piden al maestro que les vuelva a explicar a los niños o incluso forman grupos de padres para que el maestro les explique a ellos.

La principal dificultad encontrada en los tres contextos estudiados fue la falta de conocimientos para poder ayudar de mejor manera a sus hijos. Ninguno de los padres refirió sentirse confiado de sus conocimientos para apoyar a sus hijos.

En los contextos rurales, también tienen cierta apatía al uso del Internet. Ellos mencionan que los libros son sus principales fuentes de consulta, pero que actualmente ya no son de mucha ayuda debido a que sólo traen páginas de Internet y carecen de información que les pueda servir.

Una madre comenta: "Leo el libro y lo que sé, le explico, y si no, mi otro hijo".

\section{Tiempo y espacio proporcionado para el estudio}

La mayor parte de los padres refirieron que los niños realizan la tarea después de comer y el lugar más mencionado para realizarla es la mesa o el comedor, independientemente del contexto. Pocos padres designaron y acondicionaron el lugar con los materiales necesarios para realizar esta actividad.

Un dato importante en el que coincidieron los tres contextos es que mientras se realiza la tarea no está prendido el televisor en 
casa porque los distrae, y cuando se termina la tarea, se limpia el área de trabajo. Al respecto, una madre dijo: "En mi caso, con la tarea no termina la labor, tiene que limpiar todo el lugar".

\section{Repaso y evaluación}

Para saber si sus hijos están preparados para los exámenes, los padres de contextos urbanos hacen un cuestionario o realizan preguntas de los libros, aunque la mayoría de los niños ya son independientes y solos se sientan a repasar, mientras que en los contextos rurales los niños toman su cuaderno y repasan.

Cuando se preparan para una exposición, en los tres contextos piden que hagan un simulacro, que expongan para sus padres, y de esa manera se dan cuenta si ya están preparados o hay algún detalle en el cual trabajar.

La situación familiar, de empleo y otras demandas familiares que probabilizan o dificultan el apoyo

Los padres dividieron sus opiniones respecto a si el trabajo repercute o no en la calidad del tiempo que le dedican a ayudar a sus hijos. Algunos de los participantes refieren que el trabajo o las otras actividades que tienen durante el día no repercuten en el tiempo y el apoyo que les dan a sus hijos, porque independientemente de sus ocupaciones siempre van a buscar la manera de priorizar el tiempo para sus hijos. Una mamá opinó: "En mi caso, no afecta el tiempo, porque yo me organizo en la mañana para en la tarde dedicarle el tiempo a mis hijos".

Otros opinaron lo contrario, que el tiempo de trabajo sí afecta porque no siempre tienen el tiempo para ayudarlos o revisarles bien sus trabajos o tareas.

En cuanto a las situaciones familiares que impiden que apoyen a sus hijos de mejor manera, se mencionaron la enfermedad o muerte de algún familiar, pues cambia la rutina de la familia. 


\section{Conclusiones}

En los tres contextos de estudio se presentaron coincidencias, como estar con ellos y mantener una comunicación constante, no presionarlos sino motivarlos y ser afectuosos y cálidos con ellos, establecer horarios y enseñarlos a ser independientes; sin embargo, es necesario cuestionar la política educativa mexicana y el papel real que se le ha concedido a la familia en el aprendizaje de los estudiantes, dentro y fuera de las aulas.

\section{Referencias}

Bazán, A. y Domínguez, L. (En dictamen). Parents Support as Predictor of the Performance in Three Language Skills by Mexican Fifth Graders.

Bazán, A., Osuna, B. y Ross, G. (2003). Interés familiar, opinión del maestro y desempeño en lectura y escritura en niños de primaria. Revista Mexicana de Psicología, 20, 255-264.

Bazán, A., Sánchez, B. y Castañeda, S. (2007). Relación estructural entre apoyo familiar, nivel educativo de los padres y desempeño en lengua escrita. Revista Mexicana de Investigación Educativa, 12(33), 701-729.

Hernández, S.R., Fernández, C. y Baptista, P. (2010). Metodología de la investigación. México: McGraw Hill.

Hoover-Dempsey, K.V., Bassler, O.C. y Brissie, J.S. (1992). Explorations in Parent-School Relations. Journal of Educational Research, 85(5), 287-294.

Hoover-Dempsey, K. y Sandler, H. (1997). Why do Parents Become Involved in their Children's Education? Review of Education Research, 67(11), 3-42.

Hoover-Dempsey, K., Walker, J., Sandler, H., Whetsel, D., Green, C., Wilkins, A. y Closson, K. (2005). Why Do You Parents Become Involved? Research Finding and Implications. Chicago Journals, 106(2), 105-130.

Renglin, G. (2002). Project Reading and Writing (R.A.w): Home Visitations and the School Involvement of High-Risk Families. Education, 123(1), 153-160. 